\title{
Therapeutic efficacy of combined administration of thymosin and oxaliplatin in elderly gastric ulcer patients and its effect on cellular immunity and matrix metalloproteinase
}

\author{
Fang Lijuan', Li Yangfan², Zhang Lixiong ${ }^{3}$ \\ ${ }^{1}$ Department of Pharmacy, Hanchuan People's Hospital, Hanchuan City, Hubei Province, ${ }^{2}$ Department of Pharmacy, Chenzhou \\ First People's Hospital, Chenzhou City, Hunan Province, ${ }^{3}$ Department of Emergency, Hanchuan People's Hospital, Hanchuan \\ City, Hubei Province
}

${ }^{*}$ For correspondence: Email: fz1194@163.com

Sent for review: 13 November 2018

Revised accepted: 17 January 2019

\begin{abstract}
Purpose: To investigate the clinical efficacy of thymosin combined with oxaliplatin and tiggio in aged gastric cancer (GC) sufferers, as well as their impact on cellular immunity and matrix metalloproteinase. Methods: Elderly GC sufferers $(n=82)$ were divided into study and control groups by random allocation (41 patients/group). Control group was treated with oxaliplatin combined with tiggio, while the study group was treated with thymopeptide injection, in addition to oxaliplatin combined with tiggio. Each treatment course lasted 21 days, and the study involved three courses. Clinical effectiveness and toxicity in the two groups were determined and compared before and after treatment.

Results: Total effectiveness in the study group $(73.16 \%)$ and disease remission $(95.11 \%)$ were superior to the corresponding values for control patients given oxaliplatin and tiggio (48.78 and $85.37 \%$, respectively, $p<0.05)$. There were markedly lower incidences of nausea, vomiting and leukopenia in the study group than in control $(p<0.05)$.

Conclusion: The use of thymosin-oxaliplatin-tigeo triple therapy for aged GC sufferers has a definite clinical benefits and low toxic side effects.
\end{abstract}

Keywords: Thymosin, Asha Leigh Per, Teggio, Gastric cancer, Cellular immunity, Matrix metalloproteinase

\begin{abstract}
This is an Open Access article that uses a funding model which does not charge readers or their institutions for access and distributed under the terms of the Creative Commons Attribution License (http://creativecommons.org/licenses/by/4.0) and the Budapest Open Access Initiative (http://www.budapestopenaccessinitiative.org/read), which permit unrestricted use, distribution, and reproduction in any medium, provided the original work is properly credited.
\end{abstract}

Tropical Journal of Pharmaceutical Research is indexed by Science Citation Index (SciSearch), Scopus, International Pharmaceutical Abstract, Chemical Abstracts, Embase, Index Copernicus, EBSCO, African Index Medicus, JournalSeek, Journal Citation Reports/Science Edition, Directory of Open Access Journals (DOAJ), African Journal Online, Bioline International, Open-J-Gate and Pharmacy Abstracts

\section{INTRODUCTION}

Gastric cancer, one of the malignant tumors of the digestive system kills about 700,000 people every year. Mortality from GC accounts for onethird of mortalities from all malignant tumors, and most of the affected are the elderly population
(70 - 80 years old) [1]. There are no typical symptoms in the early stage of GC. Therefore, most patients are diagnosed at the middle and late stages of the disease, and so lose the best opportunity for surgical treatment. Thus, chemotherapy has become the key to comprehensive treatment of GC. Owning to 
deterioration of body function in the elderly and other factors, they are unable to cope with the toxic and side effects of chemotherapy, leading to further reduction in immune function and poor curative effects. Choosing the best chemotherapeutic regimen for reducing the incidents of toxicity and side effects has become the focus of clinical treatment for elderly patients with gastric cancer. Studies have shown that platinum-containing chemotherapy can significantly improve the clinical symptoms and prolong the survival time of patients with gastric cancer.

Tiggio is a new type of fluorouracil-based chemotherapy which has achieved good results in the treatment of GC [2]. Thymosin, an immune potentiator, enhances the maturation and differentiation of $\mathrm{T}$ lymphocytes and also reduces the side effects of chemotherapy [3]. Therefore, in this study, the impact of combination treatment with thymosin, oxaliplatin and tiggio on aged GC sufferers was investigated with respect to cellular immunity, matrix metalloproteinase and endocrine function of tumors.

\section{EXPERIMENTAL}

\section{Patients' clinical profiles}

Elderly GC sufferers $(n=82)$ on admission at the Oncology Department of our hospital from August 2016 to August 2017 were selected. The criteria for inclusion were as follows: (1) those who satisfied the conditions for diagnosis of gastric cancer [4], and were confirmed by pathological, cytological and imaging examinations; (2) patients in TNM stages III to IV; (3) patients aged over 60 years, and with expected survival time over 3 months; (4) patients with at least one lesion measured according to RECIST [5]; (5) patients with normal electrocardiogram, and normal heart, liver and kidney functions, in addition to those without chemotherapy contra-indications.

Exclusion criteria: (1) patients with severe infectious diseases and psychiatric disorders; (2) patients with other malignant tumors; (3) patients with severe heart, liver and kidney dysfunction; (4) patients with gastrointestinal perforation, bleeding and other complications; and (5) patients who had poor compliance with medical advice.

The selected patients comprised 53 men and 29 women, in the age range of $60-87$ years (mean age $=66.79 \pm 11.45$ years). With respect to cancer sites, there were 29 corpus, 19 gastric antrum and 34 fundus cases. The pathological classification showed 11 cases of welldifferentiated adenocarcinoma, 66 cases moderately poorly differentiated adenocarcinoma, and 5 cases mucinous adenocarcinoma. There were 17 cases of bone metastasis, 9 cases of liver metastasis, and 3 cases of lymphatic metastasis. The patients were randomly divided into study group and control group (41 patients/group). There were no significant differences in age, gender, TNM stage and pathological type amongst patients in both categories $(p>0.05)$.

This research was approved by the Ethical Committee of Hanchuan People's Hospital, No. 1 People's Avenue, Jingmen City, Hubei Province (approval no. 20189101), and performed according to the guidelines of Declaration of Helsinki promulgated in 1964, as amended in 1996 [6].

Table 1: General clinical profile of the patients

\begin{tabular}{|c|c|c|c|}
\hline \multicolumn{2}{|l|}{ Variable } & \multirow{3}{*}{$\begin{array}{l}\begin{array}{c}\text { Study } \\
\text { group } \\
(\mathbf{n}=\mathbf{4 1})\end{array} \\
26 / 15 \\
67.87 \pm \\
12.35\end{array}$} & $\begin{array}{c}\text { Control } \\
\text { group } \\
(\mathrm{n}=41)\end{array}$ \\
\hline Gender & Male/female & & \\
\hline Age & average age & & $\begin{array}{l}66.98 \pm \\
13.21\end{array}$ \\
\hline $\begin{array}{l}\text { Cancer site } \\
\text { (cases) }\end{array}$ & $\begin{array}{l}\text { Gastric body } \\
\text { Gastric antrum } \\
\text { Pylorus }\end{array}$ & $\begin{array}{l}15 \\
14 \\
16\end{array}$ & $\begin{array}{l}14 \\
9 \\
18\end{array}$ \\
\hline \multirow{2}{*}{$\begin{array}{l}\text { Disease } \\
\text { staging } \\
\text { (cases) }\end{array}$} & Phase III & 27 & 28 \\
\hline & Stage IV & 14 & 13 \\
\hline \multirow{3}{*}{$\begin{array}{l}\text { Pathological } \\
\text { typing } \\
\text { (cases) }\end{array}$} & $\begin{array}{l}\text { Well } \\
\text { differentiated } \\
\text { adenocarcinoma }\end{array}$ & 6 & 5 \\
\hline & $\begin{array}{l}\text { Neutralized } \\
\text { adenocarcinoma }\end{array}$ & 32 & 34 \\
\hline & $\begin{array}{l}\text { Mucinous } \\
\text { adenocarcinoma }\end{array}$ & 3 & 2 \\
\hline \multirow{3}{*}{$\begin{array}{l}\text { Transfer } \\
\text { site (cases) }\end{array}$} & Bone metastasis & 8 & 9 \\
\hline & Liver metastasis & 4 & 5 \\
\hline & $\begin{array}{l}\text { Lymphatic } \\
\text { transfer }\end{array}$ & 2 & 1 \\
\hline
\end{tabular}

\section{Treatments}

The patients in the control group were treated with oxaliplatin combined with tiggiol regimen. On the first day, oxaliplatin $\left(130 \mathrm{mg} / \mathrm{m}^{2}\right)$ was slowly and intravenously dripped for $2 \mathrm{~h}$ once a day. From the first to the 14th day, tiggio capsules were orally taken after meals twice a day. The study group was treated with thymosin, in addition to the chemotherapy regimen in the control group. The treatment involved $80 \mathrm{~mL}$ of thymosin in $500 \mathrm{~mL}$ of $5 \%$ glucose given intravenously, once a day. One treatment course was 21, and there were three courses of treatment. The two groups were not given any 
other anticancer drugs. During the treatment period, they were closely observed. In order to give symptomatic treatment for toxic and side effects, the heart, liver and kidney functions were determined regularly.

\section{Therapeutic indices}

Fasting venous blood was collected before and after treatment for both groups. Serum samples were obtained by centrifugation and kept in refrigerator below $20^{\circ} \mathrm{C}$.

\section{Efficacy}

Curative effect was evaluated in line with the evaluation standard of solid tumor treatment effectiveness standard (RECIST), with the following criteria: (a) Complete remission (CR): complete disappearance of lesion sustained for at least 4 weeks; (b) Partial remission (PR): $50 \%$ decrease in the sum of the maximum vertical diameter product, for a minimum period of 28 days; (c) Stability (SD): $<50 \%$ decrease in the sum of the maximum vertical transverse diameter product of the tumor lesion, or less than $25 \%$ increase in same, lasting for at least 4 weeks. Progression (PD): at least one lesion increased by $>25 \%$. Total effectiveness (ORR) and CBR were calculated as in Equations 1 and 2.

$$
\begin{aligned}
& O R R=\{(C R+P R) / D\} 100 \ldots \ldots \\
& C B R=\{(C R+P R+S D) / T\} 100
\end{aligned}
$$

where $\mathrm{D}$ and $\mathrm{T}$ are total number of disease remissions, and total effectiveness, respectively.

\section{Cellular immune function}

Serum T lymphocytes (CD3+, CD4+, CD8+, CD4+ and CD8+) of all patients were determined using flow cytometry, while matrix metalloproteinase (MMP-2) and matrix metalloproteinase-9 (MMP-9) levels were evaluated with enzyme-linked immunosorbent assay (ELISA).

\section{Tumor endocrine markers}

Vascular endothelial growth factor A (VEGF-A), VEGF-C, and VEGF receptor 1 (VEGFR-1) were determined with ELISA.

\section{Statistical analysis}

Measurement data are expressed as mean \pm standard deviation ( $\bar{x} \pm s$ ). Groups were compared using Student's $t$-test. Numeric data are expressed as numbers (percentage) i.e., $\mathrm{n}$ $(\%)$, and were analyzed using Chi square $\left(X^{2}\right)$ test via SPSS16.0 (IBM, USA). Values of $p<$ 0.05 were considered statistically significant.

\section{RESULTS}

\section{Clinical efficacy of the treatments}

As shown in Table 2, after treatment, the total effectiveness and disease remission in the study group were 73.16 and $95.11 \%$, respectively, and were superior to the corresponding values in control patients (48.78 and $85.37 \%$, respectively, $p<0.05)$.

\section{Cellular immune status}

As shown in Table 3, before treatment, CD3+, CD4+, CD8+ and CD4+/CD8+ levels were comparable amongst patients in both groups $(p>$ 0.05). However, after treatment, these parameters were markedly increased, relative to pre-treatment levels, except CD8+ which was less than the corresponding pre-treatment level $(p<0.05)$. There was markedly greater improvement in the thymosin-treated patients than in control patients $(p<0.05)$.

Table 2: Clinical effectiveness of the treatments $\{n(\%)\}$

\begin{tabular}{lcccccc}
\hline Group & CR & PR & SD & PD & ORR & CBR \\
\hline Control & $2(4.88)$ & $18(43.90)$ & $15(36.59)$ & $6(14.63)$ & $20(48.78)$ & $35(85.37)$ \\
Study & $6(14.63)$ & $24(58.53)$ & $9(21.95)$ & $2(4.88)$ & $30(73.16){ }^{*}$ & $39(95.11){ }^{*}$
\end{tabular}

Table 3: Cellular immune levels of patients (mean \pm SD)

\begin{tabular}{llcccc}
\hline Group & Period & CD3+ (\%) & CD4+ (\%) & CD8+ (\%) & CD4+/CD8+ (\%) \\
\hline Control & Pre-treatment & $53.38 \pm 5.24$ & $29.12 \pm 5.10$ & $36.86 \pm 6.25$ & $1.03 \pm 0.35$ \\
& After treatment & $59.27 \pm 5.63$ & $34.18 \pm 5.30$ & $32.77 \pm 3.45^{\circ}$ & $1.21 \pm 0.45$ \\
Study & Before treatment & $53.18 \pm 5.03$ & $29.96 \pm 4.35$ & $36.58 \pm 6.08$ & $1.01 \pm 0.38$ \\
& After treatment & $66.90 \pm 5.89^{\text {\# }}$ & $41.69 \pm 5.23^{\text {*\# }}$ & $26.34 \pm 4.03^{\text {\#\# }}$ & $1.38 \pm 0.29^{\text {\#\# }}$ \\
\hline
\end{tabular}

${ }^{\star} P<0.05$, relative to pre-treatment value; $\# p<0.05$, relative to control 


\section{Matrix metalloproteinase levels in the patients}

Before treatment, MMP-2 and MMP-9 levels were comparable between both categories of patients $(p>0.05)$. However, post-treatment MMP-2 and MMP-9 values were markedly reduced in both groups, but were significantly lower in the study group than in the control group $(p<0.05)$. These results are displayed in Table 4.

Table 4: Matrix metalloproteinase levels before and after treatment between the two groups $(\bar{x} \pm s)$

\begin{tabular}{llcl}
\hline Group & Time & MMP-2 $(\mathbf{n g} / \mathbf{m L})$ & MMP-9 $(\mathbf{n g} / \mathbf{m L})$ \\
\hline Control & A & $117.08 \pm 12.23$ & $407.36 \pm 108.95$ \\
& B & $81.70 \pm 10.50^{*}$ & $292.15 \pm 94.32^{*}$ \\
Study & A & $115.36 \pm 13.78$ & $409.98 \pm 119.23$ \\
& B & $57.93 \pm 8.78^{*} \#$ & $199.21 \pm 66.32^{*} \#$ \\
\hline
\end{tabular}

$\mathrm{A}$, before treatment; $\mathrm{B}$, after treatment; ${ }^{*} P<0.05$, relative to value before treatment; $\# p<0.05$, relative to control

\section{Tumor endocrine indices}

Before treatment, VEGFA, VEGFC and sVEGFR-1 levels were comparable in patients in both groups $(p>0.05)$. After treatment, VEGFA and VEGFC in the study group were decreased markedly, relative to levels in control, while sVEGFR-1 was significantly increased $(p<0.05$; Table 5).

Table 5: Tumor endocrine markers, pre- and posttreatment (mean \pm SD)

\begin{tabular}{llccc}
\hline Group & Period & $\begin{array}{c}\text { VEGFA } \\
\text { (ng/L) }\end{array}$ & $\begin{array}{c}\text { VEGFC } \\
\text { (ng/L) }\end{array}$ & $\begin{array}{c}\text { sVEGFR- } \\
\text { 1 (ng/L) }\end{array}$ \\
\hline Control & A & $209.84 \pm$ & $90.25 \pm$ & $214.36 \pm$ \\
& & 89.45 & 19.58 & 45.88 \\
& B & $103.77 \pm$ & $38.14 \pm$ & $537.45 \pm$ \\
& & $75.46^{\star \#}$ & $10.89^{* \#}$ & $61.23^{* \#}$ \\
Study & A & $203.15 \pm$ & $87.26 \pm$ & $217.56 \pm$ \\
& & 81.68 & 21.36 & 49.58 \\
& B & $165.52 \pm$ & $47.46 \pm$ & $496.25 \pm$ \\
& & $75.36^{*}$ & $1.36^{\star}$ & $67.86^{\star}$ \\
\hline
\end{tabular}

$\mathrm{A}$, before treatment; $\mathrm{B}$, after treatment; ${ }^{*} P<0.05$, relative to pre-treatment value; $\# p<0.05$, relative to control

\section{Adverse reactions}

As shown in Table 6, during the treatment period, there were no serious side effects such as liver, kidney dysfunction, diarrhea and peripheral nerve inflammation in the two groups. However, post-treatment incidents of nausea, vomiting, leukopenia and neutropenia in patients in the study group were markedly lesser in the thymosin-treated patients than in control patients $(p<0.05)$.

\section{DISCUSSION}

Studies have shown that the occurrence of gastric cancer is closely related to diet, smoking, Helicobacter pylori infection and host genetic susceptibility $[7,8]$. Effective inhibition of tumor development and prolongation of patient survival have become the focus of current research on gastric cancer. Currently, the popular chemotherapeutic drugs include platinum, fluorouracil and purple shirts. Oxaliplatin is a broad-spectrum anticancer drug which rapidly binds to DNA in vivo and has high anti-tumor activity [9]. Being a third-generation fluorouracil derivative composed of oltipraz, gemcitabine and tegafur, teggio has high bioavailability and long duration of action, and can be combined with oxaliplatin. This effectively improves the therapeutic effect against gastric cancer, but the combination of the two drugs affects the normal cells of the body while killing the tumor cells, a situation which further compromises the immunity of patients and reduces their quality of life [10].

Thymosin, an immune enhancer, regulates and enhances cellular immunity. In this study, the combination of thymosin and chemotherapy drugs for gastric cancer treatment achieved excellent curative effects. After treatment, the total effectiveness and disease remission in the study group were 73.16 and $95.11 \%$, respectively, and were significantly higher than corresponding values in the control group (78.78 and $85.37 \%$, respectively). In addition, incidents of nausea, vomiting, leukopenia and neutropenia in the study group were markedly reduced in the study group.

These results indicate that combination therapy with thymosin and oxaliplatin for gastric cancer patients can effectively reduce the infiltration of tumor cells and prevent the development of the disease [11].

Table 6: Toxic and side effects $\{n(\%)\}$

\begin{tabular}{lccccccc}
\hline Group & Nausea & Vomiting & Leucopenia & Neutropenia & $\begin{array}{c}\text { Abnormal } \\
\text { kidney function }\end{array}$ & Diarrhea & $\begin{array}{c}\text { Peripheral } \\
\text { neuritis }\end{array}$ \\
\hline Study & $10(24.39)^{*}$ & $9(21.95)^{\star}$ & $5(12.20)^{\star}$ & $5(12.20)$ & $6(14.63)$ & $5(12.20)$ & $0(0)$ \\
Control & $19(46.34)$ & $12(29.27)$ & $11(26.82)$ & $7(17.07)$ & $8(19.51)$ & $7(17.07)$ & $1(2.44)$ \\
\hline${ }^{\star} P<0.05$, compared with control & & &
\end{tabular}


Post-treatment CD3+, CD4+ and CD8+ were markedly increased in the thymosin-treated patients, and their CD8+ levels were markedly decreased, relative to control patients. These findings confirm that the use of thymosin combined with oxaliplatin tiggiol significantly improves the cellular immunity of patients, and is significantly better than the use of oxaliplatin combined with tiggiol. These results suggest that thymosin acted like a multifunctional cytokine, inducing $\mathrm{T}$ lymphocyte differentiation and maturation, and enhancing the levels of various lymphokines and their receptors. Since T lymphocyte subsets play leading roles in immune function, the levels of $T$ lymphocytes are optimized after thymosin treatment, thereby maintaining balance in immune response, and improving immunity $[12,13]$.

Matrix metalloproteinases MMP-2 and MMP-9 are two important factors which can be effectively used to evaluate the degree of malignancy and tumors invasion. Related studies have shown that matrix metalloproteinases degrade and remodel extracellular matrices, thereby maintaining a balance in the basement membrane, and regulating tumor invasion and metastasis [14]. The results of this study showed that the combination of thymosin with oxaliplatin in the study group significantly reduced the levels of MMP-2 and MMP-9, indicating that the combination is capable of enhancing immunity and reducing the invasive ability of the tumor, thereby improving patient survival. This may be attributed to the fact that tiggio up-regulates the expression of caspase-3 by inhibiting the expression of survivin, accelerating apoptosis of tumor cells, thereby achieving anti-tumor effects $[15,16]$.

Tumor cells release large amounts of cytokines involved in tumor invasion and metastasis. Vascular endothelium is acted upon by VEGFA and VEGFC to induce endothelial cell proliferation, while VEGFR-1 antagonizes VEGFA and VEGFC, thereby reducing the invasive ability of tumor cells. Post-treatment levels of VEGFA and VEGFC in the thymosintreated patients were markedly decreased, while sVEGFR-1 was elevated. Thus, the combination chemotherapy can effectively reduce cell infiltration in gastric cancer patients and prevent the development of tumor cells.

\section{CONCLUSION}

Thymosin combined with oxaliplatin effectively enhances therapy in aged GC sufferers, and produces low toxic and side effects. The combination treatment also elevates immunity, reduces tumor invasion and metastasis, and improves tumor endocrine function. Thus, the combination treatment plan may be considered for application in clinical practice.

\section{DECLARATIONS}

\section{Conflict of Interest}

No conflict of interest associated with this work.

\section{Contribution of Authors}

We declare that this work was done by the author(s) named in this article and all liabilities pertaining to claims relating to the content of this article will be borne by the authors. All authors read and approved the manuscript for publication. Zhang Lixiong conceived and designed the study, Fang Lijuan, Li Yangfan, Zhang Lixiong collected and analyzed the data, while Zhang Lixiong wrote the manuscript.

\section{REFERENCES}

1. Fu T, Ji J F. Hot spots and problems in the diagnosis and treatment of gastric cancer. Chin J Clin Oncol 2016; 43(1): 2-5.

2. Hernández-Corroto E, Marina ML, García MC. Multiple protective effect of peptides released from Olea europaea and Prunus persica seeds against oxidative damage and cancer cell proliferation. Food Res Int 2018; 106: 458-467.

3. Fischer JC, Otten V, Steiger K, Schmickl M, SlottaHuspenina J, Beyaert R, van Loo G, Peschel C, Poeck $H$, Haas $T$, et al. A20 deletion in T cells modulates acute graft-versus-host disease in mice. Eur J Immunol 2017; 47(11): 1982-1988.

4. Hu $X$. The fourth edition of the 2014 edition of the "Guidelines for the Treatment of Gastric Cancer" in Japan. Chin J Pract Surg 2015; 35(1): 16-19.

5. Shan YF, Chen Y. Effects of Tiggio combined with oxaliplatin regimen on serum tumor markers, matrix metalloproteinases and immune function in elderly patients with gastric cancer. J Hainan Med College 2017; 23(19): 2720-2723.

6. World Health Organization. Declaration of Helsinki. $\mathrm{Br}$ Med J 1996; 313(7070): 1448-1449.

7. Guo AP, Li SY, Hang ZK. Effect of Thymosin Combined with Chemotherapy on Elderly Patients with Gastric Cancer and Its Effect on Immune Function. J Pract Geriatr 2016; 30(6): 479-482.

8. Wang J. Clinicopathologic study of advanced gastric cancer without serosal invasion in young and old patients. J Surg Oncol 2015; 63(1): 36-40. 
9. Chen A, Li CN, Hsu PI, Lai KH, Lai KH, Tseng HH, Hsu $P N$, Lo GH, Lo CC, Lin CK, Hwang IR, et al. Risks of interleukin-1 genetic polymorphisms and Helicobacter pylori infection in the development of gastric cancer. Aliment Pharmacol Ther 2015; 20(2): 203-211.

10. Maurício SF, Xiao J, Prado CM, Gonzalez MC, Correia MITD. Different nutritional assessment tools as predictors of postoperative complications in patients undergoing colorectal cancer resection. Clin Nutr 2018; 37(5): 1505-1511.

11. Shen DJ. Efficacy of tigeol combined with oxaliplatin in the treatment of advanced gastric cancer and its effect on MMP-9 and VEGF in cancer tissues. J Clin Med Pract 2015; 19(5): 41-43.

12. Hou M, Zhou NB, Li H, Wang BS, Wang XQ. Morphine and ketamine inhibit immune function of gastric cancer patients by increasing percentage of CD4+CD25+Foxp3+ regulatory $T$ cells in vitro. J Surg Res 2016; 203(2): 306-312.
13. Lu Y, Fu W, Lu X, Zhang L. Clinical efficacy and safety of tiglio combined with oxaliplatinin the treatment of advanced gastric cancer with liver metastases. Mod Oncol Med 2018; (4): 553-556.

14. Wang HZ, Li Xia, Shan XF, Li YH, Wang JS. Effects of oxaliplatin combined with tigeol on the expression of related proteins in advanced gastric cancer tissues. Chin J Prim Med Pharm 2016; 23(6): 814-817.

15. Tian S, Zou XP. Effects of Thymosin a_1 Combined with Chemotherapy on Immune Function and Quality of Life in Patients with Advanced Gastric Cancer. Chin Pharm 2015; (29): 4115-4117.

16. Ma YL, Wu CB. Effect of Balance Anesthesia and Total Intravenous Anesthesia on Blood Gas and Immune Function of Gastric Cancer Patients Treated with Laparoscopic Radical Gastrectomy. Pract J Cancer 2017; 32(1): 48-50. 